\title{
Estrutura produtiva, restrição externa e crescimento econômico: a experiência brasileira ${ }^{1}$
}

\author{
Veridiana Ramos da Silva Carvalho ${ }^{2}$ \\ Gilberto Tadeu Lima ${ }^{3}$
}

\begin{abstract}
Resumo
Analisa-se a perda de dinamismo do crescimento econômico brasileiro a partir da década de 1980, utilizando a abordagem keynesiana de crescimento sob restrição externa. Resultados empíricos revelaram que a taxa de crescimento no período 1930-2004 foi a compatível com o equilíbrio externo e que o câmbio real e o fluxo de capitais tiveram um papel reduzido na obtenção desse equilíbrio. Mas a perda de dinamismo do crescimento, a partir da década de 1980, pode ser explicada por uma maior perversidade desse equilíbrio, dado o comportamento do fluxo de capitais e do câmbio real. Nos anos 1990, por sua vez, a estratégia de desenvolvimento provocou uma quebra estrutural na elasticidade-renda das importações, fazendo com que o equilíbrio externo resultasse em uma taxa de crescimento mais baixa.
\end{abstract}

Palavras-chave: Estrutura produtiva; Restrição externa; Crescimento econômico.

\begin{abstract}
Productive structure, external constraint and economic growth: the Brazilian experience

We analyze the sharp drop in the growth rate that has been experienced by the Brazilian economy since the 1980s, using the balance-of-payments-constrained growth approach. Empirical results show that growth in the 1930-2004 period was balance-of-paymentsconstrained, with terms of trade and capital flows playing quite a minor role in the reaching of external equilibrium. The sharp drop in growth that has experienced since the 1980s, however, can be explained by a tighter external constraint, given the behavior of the terms of trade and capital flows. In the 1990s, on the other hand, a new development strategy made for a structural break in the income elasticity of imports, thus leading to a lower growth rate compatible with balance-of-payments equilibrium.
\end{abstract}

Key words: Productive structure; External constraint; Economic growth. JEL E10, E23, O11.

\section{Introdução}

Uma das questões centrais em economia brasileira contemporânea é a enorme perda de dinamismo que esta sofreu a partir da década de 1980. O que explica o fato de uma economia que cresceu, em média, 6,8\% entre 1932-1980 ter passado a crescer 2,2\% no período 1981-2004, como ilustra o Gráfico 1.

(1) Trabalho recebido em março de 2007 e aprovado em janeiro de 2008. Os seguintes interlocutores merecem nossa manifestação de agradecimento - acompanhada, é claro, da isenção de praxe por observações e comentários que permitiram aprimorar o artigo: Nelson H. Barbosa-Filho, Raul Cristovão dos Santos e dois pareceristas anônimos deste periódico.

(2) Mestre e Doutoranda em Economia pela Faculdade de Economia, Administração e

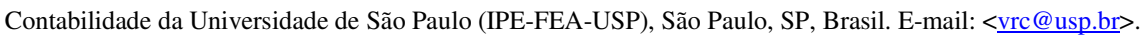

(3) Professor do Departamento de Economia da FEA-USP - agradece ao CNPq pelo suporte sob a forma de Bolsa de Produtividade em Pesquisa. E-mail: <giltadeu@usp.br>. 
Gráfico 1

Crescimento brasileiro

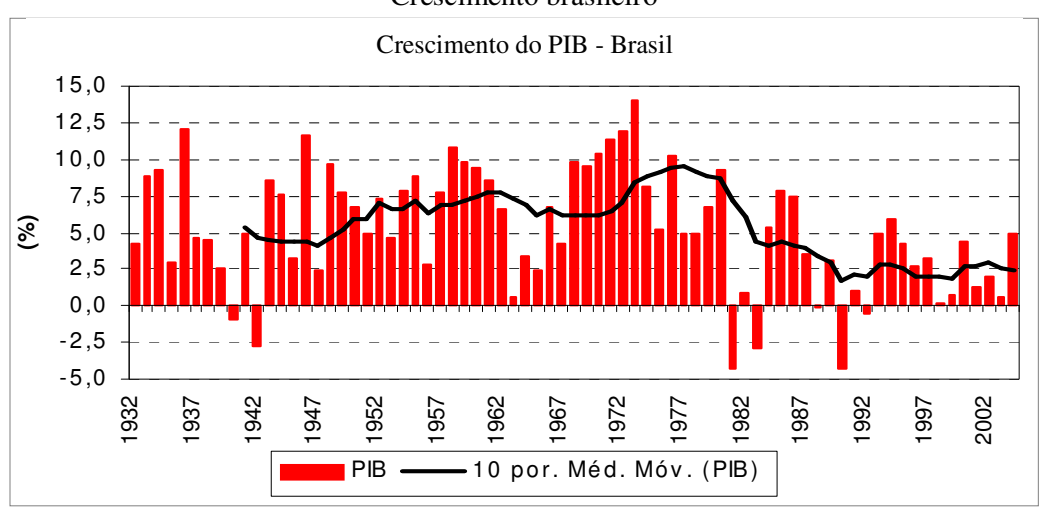

Fonte: Ipeadata.

A perda de dinamismo do crescimento econômico brasileiro iniciou-se na década de 1980, a denominada "década perdida", marcada pelo aprofundamento dos desequilíbrios macroeconômicos internos diante de uma reversão abrupta do cenário econômico internacional. Nesse contexto, propunha-se um novo modelo econômico para fazer frente à estagnação dos países em desenvolvimento. A adesão a esse novo modelo representou uma mudança na estratégia de desenvolvimento da economia brasileira, o que justifica a intensidade e a concentração das transformações ocorridas na década de 1990. Houve, nessa década, um intenso processo de abertura e de liberalização financeira, um programa de privatizações bastante extenso e uma desregulamentação da economia, modificando significativamente o papel do Estado.

Passados vários anos do início da implementação dessas reformas, é natural que se procure avaliar, ainda que de modo preliminar, parcial e tentativo, as conseqüências dessas medidas. É nesse contexto histórico que este artigo se insere e tem como objetivo principal apontar possíveis razões para o sucesso moderado das medidas adotadas nos anos 1990. Inspirado na literatura estruturalista e nas relações entre restrição externa, padrão de especialização da estrutura produtiva e crescimento econômico, este artigo testa a hipótese de que a mudança estrutural provocada pelas reformas liberalizantes dos anos 1990, ainda que tenha tido algum impacto positivo sobre a produtividade, gerou uma estrutura de especialização que piorou as condições de equilíbrio externo.

Para avaliar a relevância da restrição externa e da estrutura produtiva que a condiciona, e para entender a quebra estrutural da taxa de crescimento, será utilizada a abordagem keynesiana de crescimento sob restrição externa, formulada a partir de Thirlwall (1979). A partir dela, são realizados testes empíricos que visam a elucidar os elementos e as implicações da restrição externa sob a qual opera a economia brasileira.

O artigo está organizado da seguinte forma: a seção subseqüente apresenta não apenas algumas evidências selecionadas acerca da relação entre 
estrutura produtiva e crescimento econômico, mas, inclusive, sua motivação teórica. A Seção 2 analisa a capacidade de as reformas adotadas nos anos 1990 gerarem crescimento econômico. A Seção 3 resgata a literatura de crescimento sob restrição externa e propõe uma nova formulação que capte todos os potenciais componentes da restrição externa. A Seção 4 apresenta os testes empíricos sobre a validade da restrição externa no caso brasileiro, o papel dos diferentes componentes dessa restrição e a quebra estrutural experimentada a partir da década de 1990. A Seção 6 correlaciona os parâmetros estruturais estimados do modelo de restrição externa com diversos dados de estrutura produtiva e de competitividade. Nas considerações finais, por sua vez, sugerese uma possível explicação para a perda de dinamismo da economia brasileira iniciada nos anos 1980 .

\section{Alguns aspectos da relação entre estrutura produtiva e crescimento no Brasil}

Entre 1930 e 1980, a economia brasileira cresceu a altas taxas $(6,8 \%$ entre 1932-1980) ancoradas no Processo de Substituição de Importações (PSI). Nesse período ocorreram explícitos incentivos à industrialização por parte do Estado, seja por meio das políticas cambial, tarifária, fiscal ou via intervenção direta nos investimentos. ${ }^{4}$

Após aproximadamente 50 anos do PSI, a economia brasileira completou, no início dos anos 1980, um processo de transição, passando de uma economia agrária para uma economia industrial, com um parque industrial razoavelmente diversificado, ainda que distante da fronteira tecnológica, principalmente em alguns setores. A participação da indústria e dos serviços no produto passou de 68,4\% em 1932 para $90 \%$ em 1980 . Como ilustra o Gráfico 2, as mudanças intra-indústria são ainda mais significativas. Ao longo dos anos, o processo de transformação foi se aprofundando em direção aos setores de bens intermediários, de capital e de consumo duráveis.

Gráfico 2

Estrutura da produção industrial

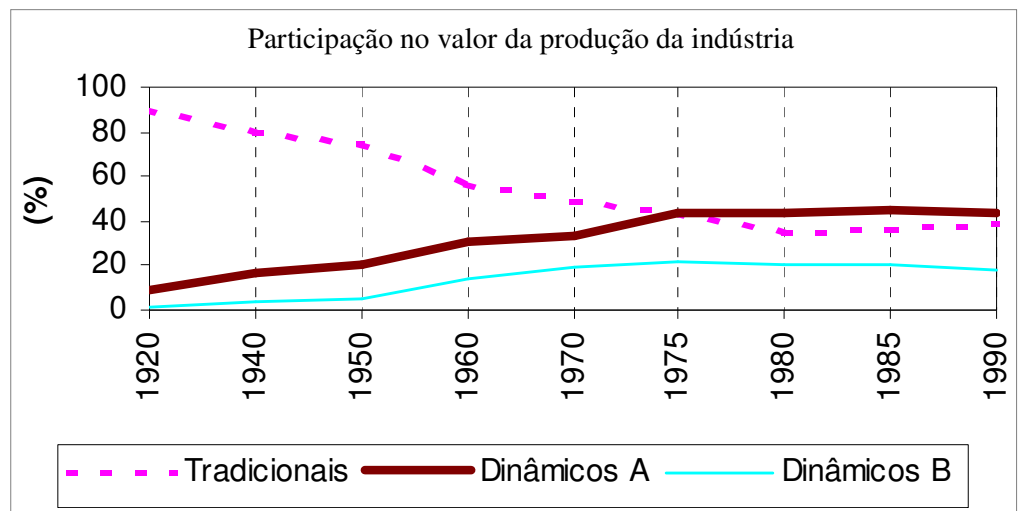

Fonte: Ipea (1998).

(4) Um detalhamento adequado do conteúdo desta e da próxima seção pode ser encontrado em Carvalho (2006, caps. 2-3). 
O diagnóstico subjacente à recomendação de direcionar os recursos do Estado para o aprofundamento da industrialização tinha origem, em grande medida, na teoria estruturalista, sistematizada e formalizada pela Cepal. Segundo tal teoria, a estrutura de produção do país tem importância essencial para o crescimento porque condiciona sua participação no comércio exterior. A especialização em produtos primários ou de baixo conteúdo tecnológico provocaria uma transferência de renda para o exterior via comércio internacional, seja mediante a deterioração dos termos de intercâmbio, seja por meio da perversidade das elasticidades, conforme argumentado por autores como Prebisch (1950), Tavares (2000) e outros autores cepalinos. ${ }^{5}$ Sob tais condições, o equilíbrio do setor externo limitaria a taxa de crescimento do país. Portanto, avançar na industrialização para setores mais complexos e de maior conteúdo tecnológico seria um meio de relaxar a restrição externa ou de diminuir a transferência de renda para o exterior.

Apesar de, inegavelmente, ter gerado um parque industrial diversificado e ter proporcionado uma alta taxa anual média de crescimento, o PSI também resultou em certos desequilíbrios. Do ponto de vista da estrutura industrial, a política econômica, que de certa forma possibilitou o seu desenvolvimento, gerou uma estrutura bastante protegida da concorrência internacional, algo que se revelou prejudicial em termos de competitividade da indústria.

Nesse contexto, o presente artigo fornece um conjunto de novas evidências empíricas para a discussão mais ampla sobre a possível necessidade de indução de uma maior diversificação da pauta industrial. Segundo Baer (1972), a maior objeção dos market critics $^{6}$ era de que o país possuía uma vantagem comparativa em produtos primários que se aprofundou no PSI. Ainda segundo eles, se o país tivesse se especializado em suas vantagens comparativas, e exportado e importado os demais bens, teria conseguido consumir mais bens do que adotando o PSI. Essa crítica foi o principal fundamento das reformas ocorridas nos anos 1990 que reverteram o processo de aprofundamento da industrialização baseada em incentivos e que em parte reverteu a estrutura produtiva às suas vantagens comparativas.

Dessa maneira, na década de 1980, o modelo adotado entre 1930-1980 entrou em crise juntamente com as enormes transformações do cenário internacional, transformações estas que se manifestaram com o primeiro choque do petróleo em 1974, e culminaram, em 1979, com um aumento abrupto da taxa de juros internacional. Nessa década, posteriormente denominada de "década perdida", o país viveu um aprofundamento dos desequilíbrios macroeconômicos. Nesse contexto, tornou-se mais intensa a percepção acerca da necessidade de mudanças no início da década de 1990.

(5) Excelentes sínteses do pensamento da Cepal são apresentadas em Rodriguez (1981) e Bielschowsky (2000).

(6) Essa classificação foi feita pelo próprio Baer (1972) referindo-se a autores críticos do PSI e que enfatizavam a crença da eficiência do mercado no direcionamento de recursos. 
O artigo de Franco (1998) delineia os principais traços da nova estratégia de desenvolvimento adotada no Brasil nos anos $1990 .^{7}$ O novo modelo proposto tem como agente do desenvolvimento o mercado, ou seja, é o livre funcionamento das forças de mercado que levará ao crescimento. Os alicerces do novo modelo são: a estabilidade, a abertura econômica e a redução do papel do Estado. No novo modelo, o Estado deve diminuir sua importância nas intervenções diretas e nos projetos de investimento, concentrando seu papel na garantia da estabilidade macroeconômica. Defende-se explicitamente o uso da poupança externa como financiador do crescimento nesse novo modelo. ${ }^{8}$ O principal alicerce desse modelo é o processo de abertura econômica que, associada à privatização e à redução do papel do Estado, causaria um abrupto crescimento da produtividade que deveria sustentar uma taxa de crescimento elevada nos anos seguintes.

Com base nesse conjunto de idéias, as reformas dos anos 1990 redefiniram o papel do Estado e fortaleceram o mercado na definição da alocação de recursos, assim como iniciaram um profundo processo de abertura da economia, tanto para os fluxos comerciais como para os fluxos de capitais. $\mathrm{Na}$ condução da política econômica, por sua vez, foi dada prioridade ao processo de estabilização, atendendo, assim, ao novo papel primordial do Estado: garantir a estabilidade macroeconômica.

\section{As conseqüiências do novo modelo econômico e o crescimento sustentado}

No final da década de 1990 já eram nítidos os resultados das reformas na economia brasileira. A privatização, a desregulamentação e, particularmente, a abertura comercial tiveram um enorme impacto sobre a produtividade e especialização da estrutura industrial. Do ponto de vista do crescimento do produto, porém, os resultados foram bem mais modestos que os idealizados.

Segundo Moreira e Correia (2004), os impactos da abertura sobre o crescimento ocorrem por meio de dois canais principais. O primeiro canal, várias vezes enfatizado por Franco (1998) ao descrever o novo modelo

(7) As reformas adotadas nos anos 1990 também foram bastante influenciadas pelo documento denominado Consenso de Washington (Williamson, 1990), que listava uma série de iniciativas pró-mercado que ajudaria os países em desenvolvimento a se ajustarem diante da crise externa dos anos 1980.

(8) Uma análise crítica da estratégia de crescimento com poupança externa adotada no Brasil, e que é compatível com a abordagem do crescimento sob restrição externa na tradição de Thirlwall seguida no presente artigo, é feita em Bresser-Pereira e Nakano (2003) e Bresser-Pereira e Gala (2007). Tendo em mente especialmente o México, o Brasil e a Argentina, Bresser-Pereira e Nakano (2003) sustentam que o modelo de crescimento com poupança externa perpetua a instabilidade macroeconômica e finda levando o país a uma crise interna e a uma crise de endividamento, já que provoca a sobrevalorização da moeda local. Embora o ingresso de poupança externa eleve ligeiramente o investimento num primeiro momento, não finda criando condições para o pagamento no futuro dessa dívida mais elevada. Bresser-Pereira e Gala (2007), por sua vez, formalizam o argumento subjacente de que o resultado do influxo de poupança externa não é principalmente a elevação da taxa de investimento, mas, sim, o aumento do consumo e do endividamento externo. 
econômico, é o canal da produtividade. Ou seja, a abertura causa um choque de competitividade, que aumenta a produtividade e gera taxas maiores de crescimento. Ao analisar os dados da economia brasileira para o período, pode-se afirmar que, por meio desse canal, as reformas realmente contribuíram para o crescimento. Entre 1990-1997, a produtividade do trabalho cresceu quase $50 \%$, segundo informações das Contas Nacionais. ${ }^{9}$ É argumentado por alguns observadores, além disso, que a produtividade total de fatores (PTF) explica grande parte do crescimento dos anos 1990, ou seja, 2,1\% a 2,6\% do crescimento de $3,1 \%$ entre 1994 e $2000 .{ }^{10} \mathrm{O}$ segundo canal seria a queda do custo do investimento que, por sua vez, teria um impacto positivo na acumulação de capital. De acordo com Bacha e Bonelli (2001), o custo do investimento teria sofrido uma forte queda na década de 1990.

Embora tenha havido um aumento de produtividade e uma queda do custo do investimento, isso não gerou uma taxa de crescimento maior. $O$ presente artigo, por sua vez, aponta outro mecanismo pelo qual as reformas dos anos 1990 poderiam ter afetado o crescimento do produto no período. Estimações empíricas permitem argumentar que a mudança na estrutura produtiva provocada pelas reformas de primeira geração, em particular a abertura, além de gerar os efeitos de aumento de produtividade e queda do custo de investimento, como ressaltado por Moreira e Correia (2004), gerou uma estrutura de especialização que piorou as condições de equilíbrio externo.

Um primeiro reflexo das reformas na estrutura produtiva foi $o$ aumento dos coeficientes de comércio entre 1989 e 1998 . Nesse sentido, houve um aumento tanto do coeficiente de exportações (de cerca de $8 \%$ para $14 \%$ do produto), como do coeficiente de importações (de cerca de $4 \%$ para $19 \%$ do consumo aparente). ${ }^{11}$ Entretanto, o último impacto foi significativamente maior que o primeiro.

Tabela 1

Coeficientes de Comércio por Setores

\begin{tabular}{l|c|c|c|c}
\hline \multirow{2}{*}{ Coeficientes de Comércio } & \multicolumn{2}{|c|}{$\begin{array}{c}\text { Importação } \\
\text { (\% do Consumo Aparente) }\end{array}$} & \multicolumn{2}{c}{$\begin{array}{c}\text { Exportação } \\
\text { (\% do Produto) }\end{array}$} \\
\cline { 2 - 5 } & 1989 & 1998 & 1989 & 1998 \\
\hline Intensivos em Capital & 7,4 & 18,7 & 7,5 & 11,4 \\
\hline Intensivos em Mão-de-Obra & 1,5 & 11,6 & 6,6 & 13,3 \\
\hline Intensivos em Tecnologia & 6,9 & 32,1 & 9,3 & 23,2 \\
\hline Intensivos em Recursos Naturais & 3,2 & 8,6 & 11,3 & 18,8 \\
\hline Total da Indústria & 4,5 & 19,3 & 8,8 & 14,8 \\
\hline
\end{tabular}

Fonte: Moreira (1999).

(9) Um estudo completo sobre a evolução da produtividade do trabalho na década de 1990 pode ser obtido em Moreira (1999). Vale ressaltar que outras medidas de valor da produção levam a taxas de crescimento ainda maiores da produtividade para o período.

(10) Conforme reportado em Lisboa (2002).

(11) Dados levantados por Moreira (1999). 
Por seu turno, o comportamento setorial desses coeficientes de comércio revela informações importantes sobre a reestruturação produtiva que a economia brasileira vivenciou na década de 1990. No que diz respeito aos coeficientes de importação, parece claro, segundo a Tabela 1, que o impacto foi bastante diferenciado entre os setores. O maior impacto, em termos de penetração das importações, ocorreu no setor intensivo em tecnologia, seguido pelo setor intensivo em capital. Nos setores intensivos em mão-de-obra e, em último lugar, os intensivos em recursos naturais, o aumento da penetração das importações foi significativamente mais suave.

Embora a evidência internacional sustente que setores intensivos em tecnologia devem apresentar um coeficiente de abertura maior, como reporta Moreira (1999), o problema, no caso brasileiro, parece residir no fato de que esse aumento da penetração do comércio exterior, particularmente nos setores de tecnologia e capital, ocorreu muito mais do lado das importações do que das exportações, o que indica um aprofundamento do comércio interindústria e não intra-indústria. Ou seja, em termos de participação no comércio internacional, claramente ocorreu uma especialização no setor intensivo em recursos naturais em detrimento dos setores intensivos em tecnologia e capital. Além disso, como destacam Resende e Anderson (1999), mesmo dentro dos setores intensivos em capital e tecnologia parece ter havido uma especialização em bens de menor conteúdo tecnológico.

Apesar disso, adeptos do novo modelo argumentam que o país se especializou em setores nos quais possuía maiores vantagens comparativas, aumentando a eficiência e, com isso, afetando o crescimento via aumento da produtividade. Essa argumentação tradicional, porém, deriva de uma literatura que não explora outra conseqüência, que é, por seu turno, bastante estudada nas abordagens (neo)estruturalista e keynesiana de crescimento sob restrição externa, ou seja, os efeitos eventualmente negativos dessa especialização produtiva sobre o equilíbrio externo e, através dele, sobre o crescimento. A conjectura que orientou o experimento empírico realizado no presente artigo foi a de que esses efeitos podem explicar o crescimento modesto do produto entre 1990-2004.

\section{A abordagem da restrição externa ao crescimento econômico de longo prazo}

O estudo empírico reportado e comentado no que segue investigou as relações entre estrutura produtiva e crescimento econômico que se expressam por meio das condições de equilíbrio das contas externas. Para tanto, fez-se uso de uma abordagem ao crescimento econômico sob restrição externa elaborada pelo economista inglês Anthony Thirlwall. Enquanto a abordagem convencional do crescimento econômico, seja na formulação de Solow (1956) ou na tradição da nova teoria do crescimento (apresentada, por exemplo, em Aghion e Howitt, 1998), focaliza exclusivamente os determinantes da 
expansão do produto no lado da capacidade de oferta, Thirlwall, por seu turno, supõe que, em geral, antes de exaurir-se essa capacidade, restrições na demanda agregada apresentam-se como fator de limitação mais significativo. Além disso, no contexto de economias abertas, Thirlwall assinala que as restrições quanto à disponibilidade de divisas tendem a apresentar-se como o principal obstáculo a níveis mais elevados de demanda agregada. Dado certo estado das artes quanto à competitividade externa de um país, algo que se refletirá em suas exportações e na demanda por importações, não há como o crescimento econômico escapar da restrição colocada pela circunstância de que os pagamentos em divisas não podem ser, no longo prazo, superiores às receitas em divisas, sob quaisquer que sejam as modalidades destas últimas.

É fundamental esclarecer que a abordagem do crescimento sob restrição externa na tradição de Thirlwall, embora esteja assentada no pressuposto de que restrições na demanda agregada apresentam-se como fator de limitação mais significativo ao crescimento no longo prazo, não ignora a relevância de fatores associados à oferta agregada. Afinal, as elasticidadesrenda do comércio internacional têm uma natureza de Janus: se, por um lado, são determinantes da demanda agregada, são o reflexo, por outro lado, de uma variedade de fatores em nível de oferta que condicionam a competitividade estrutural da economia. ${ }^{12}$

Em sua formulação inicial, Thirlwall (1979) assim especifica a condição de equilíbrio externo:

$$
P_{d} X=P_{f} M E
$$

em que $X$ é a quantidade de exportações de bens e serviços não-fatores, $P_{d}$ é o preço das exportações em moeda nacional, $M$ é a quantidade de importações de bens e serviços não-fatores de produção, $P_{f}$ é o preço das importações em moeda estrangeira e $E$ é a taxa de câmbio nominal. Nessa formulação inicial, portanto, o equilíbrio externo envolve somente a balança comercial. Expressando as variáveis da eq. (1) em termos de taxa de crescimento, obtém-se:

$$
p_{d}+x=p_{f}+m+e
$$

em que as letras em minúsculo indicam as respectivas taxas de crescimento. Adotando formas multiplicativas tradicionais, com elasticidades constantes, para as importações e as exportações, obtêm-se:

$$
M=a\left(\frac{P_{f} E}{P_{d}}\right)^{\psi} Y^{\pi}
$$

(12) Como já assinalado, por exemplo, em McCombie e Thirlwall (1994): "Income elasticities determine the balance-of-payments constrained growth rate, but the supply characteristics of goods (such as their technical sophistication, quality, etc.) determine relative income elasticities. In this important respect, there can be a marrying of the demand and supply side explanations of the comparative growth performance of nations" (p. 391). 


$$
X=b\left(\frac{P_{d}}{P_{f} E}\right)^{\eta} Z^{\varepsilon}
$$

em que $a$ e $b$ são constantes positivas, $\psi$ é a elasticidade-preço da demanda por importações, $\eta$ é a elasticidade-preço da demanda por exportações, $Y$ é a renda doméstica, $Z$ é o nível da renda mundial, $\pi$ é a elasticidade-renda da demanda por importações, enquanto $\mathcal{E}$ é a elasticidade-renda da demanda por exportações. Colocando as variáveis das eqs. (3) e (4) em termos de taxa de crescimento, obtêm-se:

$$
\begin{aligned}
& m=\psi\left(p_{f}+e-p_{d}\right)+\pi y \\
& x=\eta\left(p_{d}-e-p_{f}\right)+\varepsilon z
\end{aligned}
$$

Por meio da substituição das eqs. (5) e (6) na eq. (2) obtém-se a taxa de crescimento restringida pelo equilíbrio externo:

$$
y_{b p}=\frac{(1+\eta+\psi)\left(p_{d}-e-p_{f}\right)+\varepsilon z}{\pi}
$$

Nessa formulação inicial, assim como nas seguintes, Thirlwall (1979) supõe que no longo prazo a variação nos termos de troca, se alguma, é negligenciável, com que a eq. (7) se reduz a:

$$
y_{b p}=\frac{x}{\pi}
$$

posto que $x=\varepsilon z$ é a taxa de crescimento das exportações. ${ }^{13}$ Assim sendo, $y_{b p}$ representa a taxa de crescimento do produto consistente com a satisfação da restrição relativa ao estabelecimento do equilíbrio externo, expressando aquela que veio a ficar conhecida como Lei de Thirlwall.

Empiricamente, enquanto a Lei de Thirlwall parecia explicar razoavelmente bem a experiência de crescimento dos países desenvolvidos, o mesmo não parecia ocorrer ao serem introduzidos na amostra países em estágio inferior de desenvolvimento. A discrepância entre a taxa de crescimento dada pela Lei de Thirlwall e a taxa de crescimento efetiva, mais significativa para países em desenvolvimento, poderia ser explicada por variações no câmbio real ou nos fluxos de capital.

A primeira tentativa de incorporar o fluxo de capitais no modelo foi feita por Thirlwall e Hussain (1982). A principal implicação é que não haveria problema se um país incorresse em déficits comerciais, desde que conseguisse

(13) Como reconheceu Thirlwall, essa expressão para $y_{b p}$ é equivalente a uma versão dinâmica do multiplicador de comércio internacional de Harrod (1933) - do qual, porém, o autor alegou não ter conhecimento quando de sua derivação da expressão para $y_{b p}$. Thirlwall (1983), por sua vez, mostra que os modelos de desenvolvimento desigual de Prebisch (1950), Seers (1962) e Kaldor (1970), quando reduzidos à sua essência, igualmente associam diferenças entre taxas nacionais de crescimento a diferenças em nível de elasticidades-renda de exportações e importações. 
financiá-los com influxo de capitais, com que esse influxo poderia representar um alívio que permitiria ao país sustentar uma taxa de crescimento elevada. Contudo, a zeragem da taxa de crescimento dos fluxos de capitais, ou ainda pior, essa taxa se tornar negativa (afluxo de capitais), poderia vir a deprimir a taxa de crescimento e mesmo torná-la negativa.

Embora incorpore fluxos de capital, essa versão de Thirlwall e Hussain (1982) não leva em conta o endividamento externo acumulado, ao qual corresponde serviço de juros. As várias implicações desse endividamento externo, inicialmente consideradas em McCombie e Thirlwall (1997), recebem um tratamento algo mais completo em Moreno-Brid (1998-1999), no qual a taxa de crescimento compatível com o equilíbrio externo é derivada a partir de uma restrição externa que incorpora uma relação estável entre a dívida externa e o produto. Elliot e Rhodd (1999), por seu turno, incorporam endividamento externo e seu serviço ao modelo elaborado em Thirlwall e Hussain (1982), enquanto Moreno-Brid (2003) incorpora o serviço de juros da dívida externa, cuja não-consideração na versão anterior de seu modelo configurava uma séria limitação que já havia sido apontada por Barbosa-Filho (2001). ${ }^{14}$ Moreno-Brid (2003) submete ao teste empírico, para o caso mexicano, a especificação original de Thirlwall (1979) e suas próprias especificações (Moreno-Brid 1998-1999; 2003). Santos, Lima e Carvalho (2005), por sua vez, submetem ao teste empírico, para o caso brasileiro entre 1948 e 2004, a especificação original de Thirlwall (1979) e a especificação de Moreno-Brid (2003), obtendo resultados comprobatórios (e numericamente próximos) da abordagem do crescimento sob restrição externa em ambos os casos.

Com o objetivo de identificar o papel dos diferentes componentes do equilíbrio externo, não desconsiderando, a priori, nenhum de seus elementos, o presente artigo adota uma especificação do balanço de pagamentos que incorpora termos de troca, fluxo de capitais, sem considerar qualquer restrição à sua entrada, e o pagamento de serviços do capital, que incluirá não apenas a despesa com juros, mas toda a conta de serviços:

$$
P_{d} \mathrm{X}_{\mathrm{t}}+P_{d} \mathrm{~F}+P_{d} \mathrm{R}=P_{f} \mathrm{M}_{\mathrm{t}} \mathrm{E}_{\mathrm{t}}
$$

em que $F$ é o valor real dos fluxos de capital e $R$ é o valor real dos serviços de capital, ambos medidos em moeda estrangeira. Adotando novamente as funções de importação e exportação tradicionais, eqs. (5) e (6), expressando as variáveis na eq. (9) em termos de taxa de crescimento e substituindo as eqs. (5) e (6), obtém-se a seguinte expressão para a nova formulação:

(14) Em um padrão próximo ao de livro-texto, McCombie e Thirlwall (1994) reportam e comentam o estado das artes - no início da década de 1990 - do debate teórico-formal e empírico acerca da abordagem do crescimento sob restrição externa de Thirlwall. Por seu turno, a coletânea organizada por McCombie e Thirlwall (2004) republica vários dos principais artigos dessa literatura - assinados pelo próprio Thirlwall ou não - citados ao longo deste artigo, contando com uma introdução na qual os organizadores sintetizam o estado das artes vigente no início da década de 2000. 


$$
y_{b}=\frac{\theta_{1} x+(1+\varphi)\left(\mathrm{p}_{\mathrm{d}}-e-\mathrm{p}_{\mathrm{f}}\right)-\theta_{2} \mathrm{r}+\left(1-\theta_{1}+\theta_{2}\right) \mathrm{f}}{\pi}
$$

em que as letras minúsculas representam as taxas de variação das respectivas variáveis, enquanto $\theta_{1}$ e $\theta_{2}$ são as seguintes razões medidas no período inicial:

$$
\begin{aligned}
& \theta_{1}=\frac{\mathrm{P}_{\mathrm{d}} \mathrm{X}}{\mathrm{P}_{\mathrm{f}} \mathrm{EM}} \\
& \theta_{2}=\frac{\mathrm{P}_{\mathrm{d}} \mathrm{R}}{\mathrm{P}_{\mathrm{f}} \mathrm{EM}}
\end{aligned}
$$

A abordagem do crescimento sob restrição externa na tradição de Thirlwall tem sido validada por uma variedade de evidências empíricas para diversos países. ${ }^{15}$ Entre os estudos empíricos sobre o Brasil, ou que incluem o Brasil em sua amostra, têm-se os trabalhos de Thirlwall e Hussain (1982), Lopez e Cruz (2000), Ferreira (2001), Bértola, Higachi e Porcile (2002), Jayme Jr. (2003), Holland, Vieira e Canuto (2004), Nakabashi (2006), Santos, Lima e Carvalho (2005), Vieira e Holland (2006) e Lima e Carvalho (2006). Em geral, esses estudos indicam que a abordagem do crescimento sob restrição externa na tradição de Thirlwall é validada para o caso brasileiro. Além disso, parte deles fornece evidências relativamente robustas de que variações no câmbio real não contribuíram diretamente para o crescimento brasileiro (por exemplo, Bértola; Higachi; Porcile, 2002; Santos; Lima; Carvalho, 2005). ${ }^{16}$ Ainda, vários deles indicam que a parte financeira do balanço de pagamentos, no caso brasileiro, tem se mostrado menos explicativa da dinâmica da restrição externa do que o lado real, exceto para as décadas de 1950-1960 abordadas por Thirlwall e Hussain (1982) (por exemplo, Santos; Lima; Carvalho, 2005; Lima; Carvalho, 2006).

Sendo assim, estudo empírico reportado e comentado neste artigo contribui para a literatura de duas maneiras. Primeiramente, a especificação da Lei de Thirlwall testada é a primeira que contempla todos os componentes do balanço de pagamentos: comércio internacional, termos de troca, fluxos de capital (sem a colocação de limites de entrada) e pagamento de juros. Dessa maneira será possível decompor a taxa de crescimento compatível com equilíbrio externo nesses componentes. A segunda contribuição é um teste de quebra estrutural nos anos 1980/1990, também investigando a participação de cada componente na quebra observada e procurando relacionar, de maneira exploratória, o comportamento das elasticidades-renda com indicadores de estrutura produtiva e de competitividade.

(15) Um resumo destas contribuições empíricas para diversos países pode ser encontrado em McCombie (1989, 1997) e na introdução à coletânea organizada por McCombie e Thirlwall (2004).

(16) No entanto, alguns autores, como, por exemplo, Barbosa-Filho (2001) e Vieira e Holland (2006), aventam a possibilidade de os termos de troca influenciarem os próprios parâmetros da Lei de Thirlwall, ou seja, a elasticidade-renda das importações. 
De fato, como já destacado em Thirwall (1979), as elasticidades-renda das exportações e das importações refletem fatores de competitividade nãopreço associados à estrutura produtiva da economia. Por exemplo, como posteriormente reconhecido em McCombie e Thirlwall (1994), conforme a nota 9, essas elasticidades são determinadas por características dos bens envolvidos tais como seu grau de sofisticação tecnológica. Pioneira nesse sentido foi a contribuição de Fagerberg (1988), que incorpora variáveis tecnológicas como determinantes da competitividade não-preço em um arcabouço de crescimento sob restrição externa na tradição de Thirlwall.

Mais recentemente, Verspagen (2002) e Llerena e Lorentz (2004) elaboraram interessantes modelos macroeconômicos de crescimento na tradição keynesiana com sólidos microfundamentos neo-schumpeterianos ou evolucionários, com que a interação recíproca entre as dinâmicas industrial e tecnológica subjacente ao comportamento das variáveis agregadas pode ser analisada de forma significativamente mais inclusiva que no restante da literatura, seja ela convencional ou não. Verspagen (2002), por exemplo, elabora um modelo desagregado, do tipo insumo-produto, de crescimento guiado pela demanda que opera sob uma restrição de balanço de pagamentos. A dinâmica de três variáveis de composição é modelada a partir de uma equação de replicação, com base na qual unidades que apresentam um desempenho superior à média têm sua participação no conjunto ampliada. Essas variáveis são a parcela do mercado doméstico que cabe aos produtos de cada setor (doméstico ou não) e as parcelas das exportações mundiais e da demanda agregada doméstica (consumo, investimento e exportações) que cabem a cada um deles. As elasticidades-renda das importações e das exportações, resultam, então, da operação dessas dinâmicas evolucionárias de replicação, covariando com as variáveis macroeconômicas de cuja determinação elas participam. O modelo é empregado para simular trajetórias de crescimento para a economia holandesa sob diversos cenários de mudança tecnológica, competitividade internacional e composição setorial da demanda.

Llerena e Lorentz (2004), por sua vez, desenvolvem um modelo kaldoriano de crescimento guiado pelas exportações e variação da produtividade determinada pela Lei de Verdoorn, de acordo com a qual a presença de retornos crescentes dinâmicos faz com que o crescimento da produtividade varie positivamente com o crescimento do produto. ${ }^{17} \mathrm{~A}$ mudança tecnológica subjacente à Lei de Verdoorn é microfundamentada através de um modelo evolucionário de dinâmica industrial na linha de Nelson

(17) Esse modelo de Llerena e Lorentz (2004), diferentemente daquele desenvolvido em Verspagen (2002), supõe a existência de apenas um único setor, algo que, como admitem os autores, impede a abordagem de outra temática recorrente na literatura kaldoriana, qual seja, a influência do padrão de especialização produtiva sobre a dinâmica do crescimento. Não obstante o presente artigo pretenda demonstrar que, em sendo a restrição externa aquela que tem se interposto, no longo prazo, ao crescimento brasileiro, o padrão de especialização da estrutura produtiva nacional importa, os resultados obtidos por Llerena e Lorentz (2004) merecem consideração, conforme observado a seguir. 
e Winter (1982), com ênfase nos determinantes da atividade inovativa das firmas. O objetivo do modelo é demonstrar que a divergência nas taxas de crescimento nacionais, em uma situação na qual cada país deve satisfazer uma restrição de balanço de pagamentos, pode resultar da diversidade tecnológica entre eles. Posto que as exportações de um país dependem positivamente da renda dos demais países e de sua parcela do mercado internacional, enquanto as importações dependem positivamente da renda doméstica e da parcela do mercado internacional dos demais países, os autores derivam uma versão modificada da Lei de Thirlwall. Especificamente, a taxa de crescimento de um país é dada não apenas pela razão entre as elasticidades-renda das exportações e das importações multiplicada pela taxa de crescimento dos demais países, conforme a equação (8), mas, inclusive, pela taxa de crescimento de sua parcela do mercado internacional. Esta parcela, por sua vez, depende da parcela do mercado internacional das firmas locais, cuja variação é dada por uma dinâmica de replicação. Assim, a parcela do mercado internacional de uma dada firma doméstica sobe (desce) quando sua competitividade em preço é superior (inferior) à média internacional. ${ }^{18}$

Utilizando simulações numéricas, Llerena e Lorentz (2004) analisam o efeito de quatro parâmetros sobre o crescimento relativo de um grupo de economias. Dois desses parâmetros dizem respeito à restrição externa, a saber, as diferentes elasticidades-renda das exportações e das importações, enquanto os demais referem-se ao processo de mudança tecnológica, a saber, o conjunto de oportunidades tecnológicas e a capacidade de absorção. Entre os vários resultados obtidos, dois merecem menção. Primeiro, uma elevação na heterogeneidade das elasticidades-renda das exportações e das importações aumenta a divergência entre as taxas de crescimento nacionais. Segundo, uma elevação na heterogeneidade dos conjuntos de oportunidades tecnológicas amplia a divergência entre as taxas de crescimento nacionais apenas durante um período transitório, enquanto uma ampliação no acesso a transbordamentos tecnológicos o faz de forma permanente. ${ }^{19}$

Ainda no tocante à dinâmica das elasticidades-renda do comércio internacional, merecem consideração os seguintes resultados. Bairam (1997) encontra evidências de que a elasticidade-renda das exportações varia

(18) Logo, esse componente adicional associado à competitividade da economia finda desempenhando um papel análogo àquele desempenhado pelos termos de troca na derivação original de Thirlwall (1979), conforme a equação (7). Vale lembrar que nessa derivação inicial, assim como nas seguintes, Thirlwall supõe que, no longo prazo, a variação nos termos de troca, se alguma, é negligenciável.

(19) Como reconhecem os autores, este último resultado contradiz a crença convencional de que quanto mais o conhecimento se difunde entre firmas e países e, portanto, quanto menos a tecnologia difere entre eles, menor a divergência nas taxas de crescimento nacionais. Admitindo que se trata de um resultado intrigante cuja compreensão requer análises bem mais amplas e aprofundadas, os autores conjecturam que ele pode ser devido a efeitos combinados da restrição externa e da mudança tecnológica. Vale dizer, as firmas que ganham participação de mercado eventualmente são também aquelas que mais se beneficiam dos transbordamentos tecnológicos, já que passam a contar com maiores recursos para imitar e explorar outras tecnologias. 
negativamente com o nível de renda per capita. Porém, Thirlwall (1997) argumenta que esse resultado foi influenciado pela amostra restrita do estudo, composta principalmente por países em desenvolvimento, e conjectura que essa relação tem a forma de U-invertido. A razão é que embora essa elasticidade suba conforme se eleva a parcela de manufaturados na pauta exportadora, ela diminui conforme o nível de renda se torna elevado e a estrutura industrial, em decorrência, tende a se tornar mais antiquada. $\mathrm{Na}$ mesma linha, Setterfield (1997) sugere que uma economia desenvolvida pode vir a se prender a uma estrutura industrial mais tradicional, com que a elasticidade-renda das exportações passaria a variar negativamente com o crescimento econômico prévio. McCombie e Roberts (2002), porém, sugerem que uma especificação mais apropriada estabeleceria que a razão entre as elasticidades-renda das exportações e das importações tem uma relação de Uinvertido com o crescimento prévio. A justificativa é que níveis mais baixos deste último tendem a desencadear pressões por reformas que findam reduzindo a razão de elasticidades-renda, enquanto taxas de crescimento prévio mais elevadas tendem a encorajar o aprisionamento a uma dada estrutura produtiva. Utilizando dados para a economia brasileira no período 1947-2000, Nakabashi (2007), por sua vez, não apenas corrobora, de um modo geral, o modelo de Thirlwall e Hussain (1982), mas, inclusive, encontra evidências robustas de que a elasticidade-renda das importações variou de maneira anticíclica, sendo maior em períodos de elevada liquidez externa e de alto crescimento.

\section{Resultados empíricos}

O estudo empírico realizado utilizou a metodologia proposta por McCombie (1989). Basicamente, o autor define a elasticidade-renda hipotética como sendo aquela que iguala a taxa de crescimento observada e a taxa teórica (dada pela eq. (8), no caso da especificação básica do modelo). Caso essa elasticidade-renda hipotética não seja estatisticamente diferente daquela estimada a partir da função importação efetiva, não se pode, então, refutar a hipótese de que o crescimento do país é restrito pelo equilíbrio externo. Esse método foi utilizado por Moreno-Brid (1998-1999; 2003), para o caso mexicano, e por Santos, Lima e Carvalho (2005), para o caso brasileiro.

Uma maneira análoga de aplicar essa metodologia consiste em comparar a taxa de crescimento prevista pelo modelo e a taxa de crescimento real. Primeiro, estimam-se as elasticidades-preço e renda efetivas com base em uma função importação. Em seguida, utilizam-se essas estimativas para calcular a taxa de crescimento compatível com o modelo teórico, que, no caso do presente artigo, é dada pela equação (10). Finalmente, comparam-se a taxa de crescimento prevista pelo modelo e a taxa de crescimento real, com a proximidade entre essas duas taxas validando. 


\section{Análise do período 1930-2004}

Dessa maneira, a primeira etapa do teste empírico consiste em estimar uma função importação e, assim, obter os parâmetros $\pi$ (elasticidade-renda das importações) e $\psi$ (elasticidades-preço das importações), necessários ao cálculo da taxa de crescimento compatível com o modelo teórico (eq. 10). Neste artigo, estimou-se uma função importação em sua forma mais tradicional dos modelos de crescimento com restrição externa, conforme proposto originalmente por McCombie (1989) e expresso na eq. (5). Em outras palavras, estimou-se uma formulação que contempla apenas as duas variáveis estruturais do modelo, ou seja, as elasticidades-renda e preço, sem a adição de controles ou outras variáveis. ${ }^{20}$ Assim, para o período 1930-2004, estimou-se, por meio de técnicas de cointegração, a seguinte função importação com as variáveis em nível:

$$
\log M_{t}=\pi \log \mathrm{Y}_{\mathrm{t}}+\psi \log \left(\mathrm{P}_{\mathrm{f}}+\mathrm{E}-\mathrm{P}_{\mathrm{d}}\right)
$$

Foram realizados os testes de raiz unitária com as três séries envolvidas, como pode ser visto no Anexo 1, incluindo o teste KPSS, que ao inverter a hipótese nula minimiza o problema de baixa potência do teste $\mathrm{ADF}^{21}$ Em todos os casos foi aceita a existência de uma raiz unitária. Dessa forma, como todas as variáveis são integradas de ordem 1, pode-se estimar a equação acima utilizando técnicas de cointegração.

Como pode ser observado no Anexo 2, para estimar a cointegração acima foi utilizada um VAR de ordem 1, o que corresponde a um VEC de ordem 0, com base em todos os critérios de informação e no teste de significância da maior defasagem (LR). A análise dos termos deterministas indicou o modelo mais simples, ou seja, sem intercepto ou declividade.

(20) Existe na literatura uma diversidade de estimações da função importação que propõem a inclusão de outras variáveis além da renda interna e de uma medida de preço relativo das importações. McCombie (1997) e Blecker (1992) propõem a inclusão de dummies para captar a quebra de tendência para os EUA. Já Moreno-Brid (2003) propõe a inclusão de um índice que controla por barreiras não tarifárias para o caso mexicano. No caso brasileiro, Azevedo e Portugal (1998) propõem que uma variável de utilização da capacidade seja incluída na função importação, o que explicitaria o componente cíclico da renda. Já Resende (2001) defende a adição da disponibilidade cambial, que representa a capacidade de importar, como argumento da função importação. Morais e Portugal (2004), por sua vez, ressaltam a instabilidade desses parâmetros e indicam métodos econométricos que levam em conta esse problema. Cabe ressaltar que os vários resultados das estimações da função importação são bastante sensíveis às especificações e à periodicidade adotadas.

(21) Para os dados de balanço de pagamentos entre 1947-2004, a fonte original é o Banco Central do Brasil. Já para o período entre 1930-1946, o Ipea compilou dados de diversos autores. Todas as séries de balanço de pagamentos em dólares foram deflacionadas pelo IPC norte-americano. A série de câmbio nominal entre 1942-2004 tem como fonte original o Banco Central do Brasil, e entre 1930-1942 o Ipea compilou dados de diversos autores. Quanto à construção da série de câmbio real $\left(E P_{f} / P_{d}\right)$,utilizaram-se como medida para $P_{f}$ os comercializáveis norte-americanos (IPA-EUA), e para $P_{d}$ os não comercializáveis locais (IPC-Fipe), de modo que foi adotada a medida de câmbio real mais tradicionalmente utilizada. Já para o produto real utilizou-se a medida mais tradicional, ou seja, as séries de PIB a preços constantes entre 1947-2004, que têm como fonte original o BNDES. Para o período 1930-1947, por sua vez, a série foi elaborada pelo próprio Ipea. 
Com base nessa especificação, foram feitos os testes de cointegração reportados no Anexo 3, que indicaram a existência de apenas um vetor de cointegração significante segundo a estatística do traço e do autovalor. Vale dizer, foi possível identificar apenas uma relação de longo prazo entre importações, renda e câmbio real. Por sua vez, os testes de normalidade dos resíduos, necessários para validar a análise de cointegração, estão reportados no Anexo 4.

Assim, foi estimado o seguinte vetor de cointegração normalizado pela variável importações:

Tabela 2

Estimação da função importação

\begin{tabular}{|c|c|c|c|}
\hline \multicolumn{4}{|c|}{ Vetor de Cointegração Normalizado } \\
\hline & Valor & \multicolumn{2}{|c|}{ Estatística t de Student } \\
\hline Ln Importações & 1.0000 & \\
\hline Ln Renda & -1.2093 & -31.7544 & significante \\
\hline Ln Câmbio real & -0.9312 & -1.6196 & não significante \\
\hline \multicolumn{4}{|c|}{ Coeficientes de ajustamento } \\
\hline & Valor & \multicolumn{2}{|c|}{ Estatística t de Student } \\
\hline D (Ln Importações) & 0.0146 & 1.5856 & não significante \\
\hline D (Ln Renda) & 0.0191 & 11.0736 & significante \\
\hline D (Câmbio real) & 0.0064 & 0.7493 & não significante \\
\hline \multicolumn{4}{|c|}{ Estatísticas parciais } \\
\hline & $R$ Quadrado Ajust & $\begin{array}{c}\text { Soma Quad } \\
\text { Resíduos }\end{array}$ & Max Verossimilhança \\
\hline D (Ln Importações) & -0.008293 & 3.149967 & 11.79545 \\
\hline D (Ln Renda) & 0.49961 & 0.110267 & 135.8283 \\
\hline D (Câmbio real) & 0.5241 & 2.652516 & 18.15514 \\
\hline \multicolumn{4}{|c|}{ Estatísticas gerais } \\
\hline \multicolumn{2}{|c|}{ Covariância dos Resíduos } & \multicolumn{2}{|c|}{$1.74 \mathrm{E}-06$} \\
\hline \multicolumn{2}{|c|}{ Máxima Verossimilhança Ajustada } & \multicolumn{2}{|c|}{175.7139} \\
\hline \multicolumn{2}{|c|}{ Critério de Informação de Akaike } & \multicolumn{2}{|c|}{-4.586862} \\
\hline
\end{tabular}

Ou seja, a relação de longo prazo entre importações, renda e câmbio real pode ser representada pela seguinte equação:

$$
\log M_{t}=1,21 \log \mathrm{Y}_{\mathrm{t}}+0,93 \log \left(\mathrm{P}_{\mathrm{f}}+\mathrm{E}-\mathrm{P}_{\mathrm{d}}\right)
$$

O coeficiente da renda, que representa a elasticidade renda das importações, é significante e foi estimado em 1,21 para o período 1930-2004. Já o coeficiente do câmbio real apresentou sinal oposto ao esperado, mas pode ser considerado não significante a $5 \%$ na relação de longo prazo. Note-se que 
resultado similar para o câmbio real foi encontrado por Lopez e Cruz (2000), Bértola, Higachi e Porcile (2002) e Santos, Lima e Carvalho (2005). ${ }^{22}$

Observe-se que uma série de outros artigos estima uma função importação para o Brasil para diferentes períodos, com diferentes métodos e variáveis explicativas. Ainda que essas diferenças, principalmente de período, comprometam uma comparação direta desses vários outros resultados com os obtidos neste artigo, os resultados dessas outras estimações foram reportadas no Anexo 5.

Uma vez estimadas as elasticidades-renda e preço, essas estimativas foram utilizadas para calcular o crescimento da renda compatível com o equilíbrio do balanço de pagamentos, tal como proposto na eq. (10). Além disso, a formulação proposta neste artigo permite a decomposição da taxa de crescimento do produto entre os diversos componentes do balanço de pagamentos. A Tabela 3 reporta os resultados obtidos.

Tabela 3

Contribuição dos componentes do BP no crescimento - 1930 a 2004

\begin{tabular}{|c|c|c|c|c|c|c|}
\hline $\begin{array}{l}\text { Crescimento } \\
\text { Modelo (eq. 10) }\end{array}$ & Comércio & $\begin{array}{c}\text { Termos } \\
\text { de troca }\end{array}$ & Financeiro & $\begin{array}{c}\text { Serviço } \\
\text { dívida }\end{array}$ & Capital & $\begin{array}{c}\text { Crescimento } \\
\text { efetivo }\end{array}$ \\
\hline $4,5 \%$ & $4,3 \%$ & $1,4 \%$ & $-1,2 \%$ & $-1,2 \%$ & $0,0 \%$ & $5,0 \%$ \\
\hline
\end{tabular}

A taxa de crescimento prevista pelo modelo para o período 1930-2004 foi de $4,5 \%$ a.a., valor que não pode ser considerado estatisticamente diferente da taxa efetiva que foi de $5 \%$ a.a., ao nível de significância de 5\%. Assim, valida-se empiricamente a hipótese de que o crescimento brasileiro no período 1930-2004 foi aquele compatível com a análise de crescimento restrito pelo balanço de pagamentos em uma abordagem na tradição de Thirlwall.

Em seguida, analisa-se o papel dos diferentes componentes do balanço de pagamentos. Dos 4,5\% de crescimento previsto pelo modelo, o lado comercial, ou a razão das elasticidades-renda, é responsável pela maior parte, ou seja, 4,3\%. A segunda parte mais relevante é a dos termos de troca, 1,4\%. O

(22) Sem dúvida, esses resultados que indicam a pouca significância, se alguma, da taxa de câmbio real na função importação, especialmente quando um horizonte muito longo de análise é considerado, têm implicações para a análise da validade da condição de Marshall-Lerner para a economia brasileira no longo prazo. Embora essa análise esteja além do escopo do presente artigo, um aspecto da abordagem aqui adotada merece ser destacada. Ainda que os modelos de restrição externa na tradição de Thirlwall suponham que, no longo prazo, as variações nos termos de troca são negligenciáveis, reconhece-se que, no curto prazo, essas variações tendem a desempenhar um papel fundamental no ajustamento externo e podem ter um papel relevante na determinação do crescimento econômico. Além disso, mesmo que uma especificação que admita a variabilidade dos termos de troca, quando testada, indique a não-significância dos termos de troca na determinação do produto no longo prazo, como detectado, por exemplo, em Lima e Carvalho (2006), disso não se segue necessariamente a invalidade da condição de Marshall-Lerner. Afinal, da perspectiva da abordagem keynesiana do crescimento sob restrição externa é admissível que uma depreciação cambial, mesmo que tenha um impacto positivo sobre as exportações líquidas, possa vir a afetar negativamente, e na mesma extensão, outro(s) componente(s) da demanda agregada. 
componente financeiro contribui negativamente para o crescimento $(-1,2 \%)$, sendo que o fluxo de capitais tem efeito nulo e o pagamento de serviços contribuiu negativamente em 1,2\%. Quanto à conta capital, os resultados acima parecem corroborar as hipóteses então assumidas por Ferreira (2001) de que o fluxo de capitais não contribui diretamente para o alargamento da restrição imposta pelo balanço de pagamentos e que o pagamento do serviço desse capital contribuiria para intensificar essa restrição. Adicionalmente, o papel positivo do câmbio no sentido de relaxar a restrição externa no período parece ter sido proporcionalmente compensado pelo papel restritivo do componente financeiro.

Com base nesses resultados, pode-se afirmar que entre 1930-2004 o crescimento brasileiro foi aquele compatível com o equilíbrio do balanço de pagamentos. Além disso, o lado comercial, ou a razão das elasticidades-renda, explica a maior parte desse crescimento.

Uma vez detectada a importância da restrição externa e dos seus respectivos componentes, cabe agora investigar quais deles explicam a enorme queda da taxa de crescimento do produto a partir da década de 1980.

\section{Análise de quebra estrutural}

Primeiramente, estimou-se a função importação para o período 19302004 usando o método de Mínimos Quadrados Ordinários (MQO) das variáveis em primeira diferença. ${ }^{23}$ A razão prática para se voltar à estimação por MQO é que nesse método é possível introduzir mais claramente a quebra estrutural nas elasticidades-renda via dummies de declividade. Recorreu-se a esse procedimento, considerado aqui como o método econométrico mais adequado para medir a quebra estrutural, principalmente no fim da amostra, e pelo fato de evidências empíricas apontarem que não existe uma grande perda em fazer estimativas por MQO.

Com base nessa estimação da função importação em primeira diferença, foram feitas diversas tentativas de incluir uma quebra estrutural nas elasticidades-renda e preço das importações. Essas tentativas foram embasadas na própria história econômica brasileira, ou seja, tentou-se colocar a quebra estrutural nas elasticidades nos anos 1980 (pós-1982), a partir da primeira redução tarifária expressiva (1987), a partir da intensificação da abertura (1990) e, finalmente, a partir de 1994, quando todos os elementos do novo modelo econômico - estabilidade, abertura econômica e da conta capital e desregulamentação da economia - já vigoravam.

Os resultados indicam que a elasticidade-renda das importações apresentou uma quebra estrutural significante nos anos 1990 (a partir de 1994).

(23) Diversos testes empíricos comprovaram que não existe muita diferença na estimação em primeiras diferenças por MQO ou em nível por cointegração, uma vez que a lei de Thirlwall é um modelo para a taxa de crescimento e não para o nível das variáveis. 
Quando a quebra é introduzida nos anos 1980, ela se torna não significante. Já a elasticidade-preço das importações apresenta uma quebra estrutural nos anos 1980. Esse resultado aponta na mesma direção de alguns trabalhos de estimação da demanda por importações nos anos 1980 e 1990. Uma conclusão geral desses estudos é que as importações brasileiras passaram a responder mais intensamente a variações na renda a partir da década de $1990 .^{24}$

A partir dessa indicação, foi estimada a função importação considerando as quebras estruturais. Os resultados foram reportados na tabela abaixo:

Tabela 4

Estimação da função importação

\begin{tabular}{|l|r|r|l|c|}
\hline \multicolumn{4}{|c|}{ Estimação por mínimos quadrados ordinários - Com quebra estrutural * } \\
\hline \multicolumn{4}{|c|}{ Variável Dependente: D(Importações) } \\
\hline & Coeficiente & Erro-Padrão & Estatística t & $\begin{array}{c}\text { Probabili- } \\
\text { dade }\end{array}$ \\
\hline D(Ln Renda Interna) & 1.2124 & 0.3568 & 3.3981 & 0.0011 \\
\hline D(Ln Câmbio Real) & -0.5207 & 0.1600 & -3.2551 & 0.0017 \\
\hline D(LnRenda)*Dummy 90 & 3.2430 & 1.0085 & 3.2156 & 0.0020 \\
\hline D(LogCâmbioReal)*Dummy 80 & 0.3785 & 0.1918 & 1.9734 & 0.0524 \\
\hline R-Quadrado & 0.2737 & Média Variável Dependente & 0.0426 \\
\hline R-Quadrado Ajustado & 0.2426 & S.D. Variável Dependente & 0.2069 \\
\hline S.E. da Regressão & 0.1800 & Critério Informação Akaike & -05388 \\
\hline Soma Quadrados Resíduos & 2.2690 & Critério Informação Schwarz & -0.4142 \\
\hline Max Verossimilhança & 23.9338 & Estatística Durbin-Watson & 1.7110 \\
\hline
\end{tabular}

* Erro-Padrão e Covariância com correção heterocedasticidade (White)

Dummy 90: a partir de 1993; Dummy 80: a partir de 1982

Ou seja, a elasticidade-renda das importações passou de 1,22 entre 1930-1993 para 4,46 entre 1994-2004 e a elasticidade-preço passou de -0,34 para $-0,14$ no mesmo período.

Com base nessas estimativas, foi recalculada a taxa de crescimento compatível com o equilíbrio do balanço de pagamentos para os períodos 19301993 e 1994-2004.

Tabela 5

Contribuição dos componentes do balanço de pagamentos no crescimento

\begin{tabular}{|c|c|c|c|c|c|c|c|}
\hline & $\begin{array}{c}\text { Crescimento } \\
\text { Modelo } \\
\text { (eq. 10) }\end{array}$ & Comércio & $\begin{array}{c}\text { Termos } \\
\text { de } \\
\text { troca }\end{array}$ & $\begin{array}{c}\text { Finan- } \\
\text { ceiro }\end{array}$ & $\begin{array}{c}\text { Serviço } \\
\text { dívida }\end{array}$ & Capital & $\begin{array}{c}\text { Crescimento } \\
\text { efetivo }\end{array}$ \\
\hline $\begin{array}{c}1931- \\
1993\end{array}$ & $3,8 \%$ & $7,0 \%$ & $-0,7 \%$ & $-2,5 \%$ & $-2,5 \%$ & $0,00 \%$ & $5,5 \%$ \\
\hline $\begin{array}{c}1994- \\
2004\end{array}$ & $2,8 \%$ & $1,3 \%$ & $1,7 \%$ & $-0,2 \%$ & $-0,3 \%$ & $0,02 \%$ & $2,7 \%$ \\
\hline
\end{tabular}

(24) Por exemplo, o estudo de Azevedo e Portugal (1998) para a economia brasileira constata que entre 1980 e 1989 o coeficiente da renda é estatisticamente não significante, enquanto entre 1990 e 1995 ele se torna significante e igual a 2,106 . 
Com base nos resultados acima, torna-se claro que a quebra estrutural dos anos 1990 ocorreu no lado comercial, ou seja, na razão de elasticidadesrenda do comércio exterior. O componente representado pela razão entre o crescimento das exportações e a elasticidade-renda das importações ponderada pelo desequilíbrio inicial contribuiu para um crescimento de $7 \%$ entre 19311993 e 1,3\% entre 1994-2004, resultado que explica a enorme perda de dinamismo do crescimento.

\section{Análise de determinantes do equilíbrio externo}

O desenvolvimento da análise até aqui evidencia que as variáveischave para uma adequada compreensão da perda de dinamismo do crescimento brasileiro são as elasticidades-renda das importações e das exportações. Afinal, elas explicam a maior parte do crescimento compatível com o equilíbrio do balanço de pagamentos que, por sua vez, pode ser considerado estatisticamente igual ao crescimento observado. Assim sendo, investigar os determinantes das elasticidades é algo essencial para a validação e entendimento do modelo. Nesta seção será feita uma tentativa preliminar de análise de alguns determinantes das elasticidades-renda do comércio exterior, relacionando-os com aspectos da estrutura produtiva, tarefa para a qual os vários estudos correspondentes reportados ao final da Seção 3 serão referências úteis. ${ }^{25}$

O primeiro passo foi estimar as elasticidades por período. Para isso, utilizaram-se Mínimos Quadrados Ordinários para estimar as funções importação e exportação em primeiras diferenças e foi inserida uma variável dummy de declividade para captar as modificações desses parâmetros no tempo (Anexo 6). ${ }^{26}$ Com base nessas elasticidades, realizaram-se algumas relações com indicadores de estrutura produtiva e produtividade.

Como pode ser visualizado no Gráfico 3, a participação das indústrias dinâmicas está significativamente correlacionada com o comportamento da elasticidade-renda das importações. Observa-se que esse aumento da participação das indústrias dinâmicas se reverteu nos anos 1980/1990, levando, também, a um aumento na elasticidade-renda das importações.

(25) Outra alternativa seria tentar estimar a versão desagregada da Lei de Thirlwall derivada, a partir de um arcabouço macrodinâmico multissetorial pasinettiano, em Araujo e Lima (2007). Essa versão indica que o crescimento da renda per capita é diretamente proporcional ao crescimento das exportações, sendo essa proporção inversamente (diretamente) relacionada com as elasticidades-renda setoriais das importações (exportações) ponderadas pela participação de cada setor no total correspondente. Claramente, várias implicações teóricas, empíricas e de política pública relevantes podem ser extraídas dessa abordagem multissetorial ao crescimento sob restrição externa, razão pela qual tentativas de estimá-la empiricamente têm sido parte integrante de nossa agenda de pesquisa.

(26) $\mathrm{O}$ ano atribuído à elasticidade é o ponto médio do período para o qual a elasticidade foi calculada. 
Gráfico 3

Relação entre a participação das indústrias dinâmicas (Gráfico 2) e a

Elasticidade-renda das importações

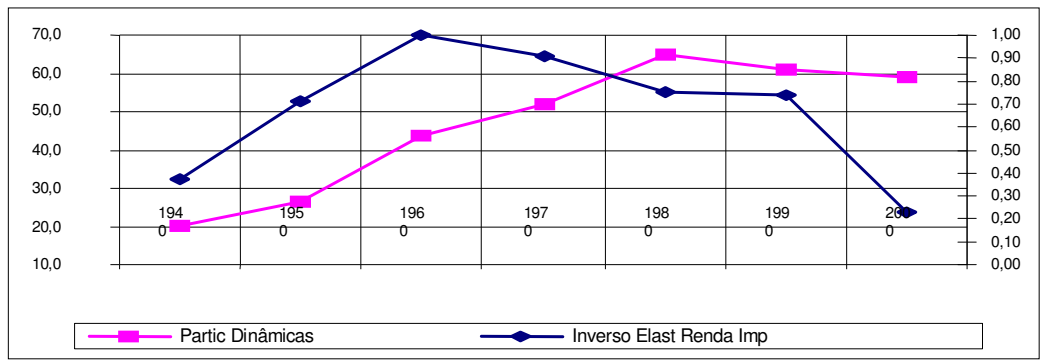

Gráfico 4

Relação entre a participação da indústria e serviços e a razão de elasticidades

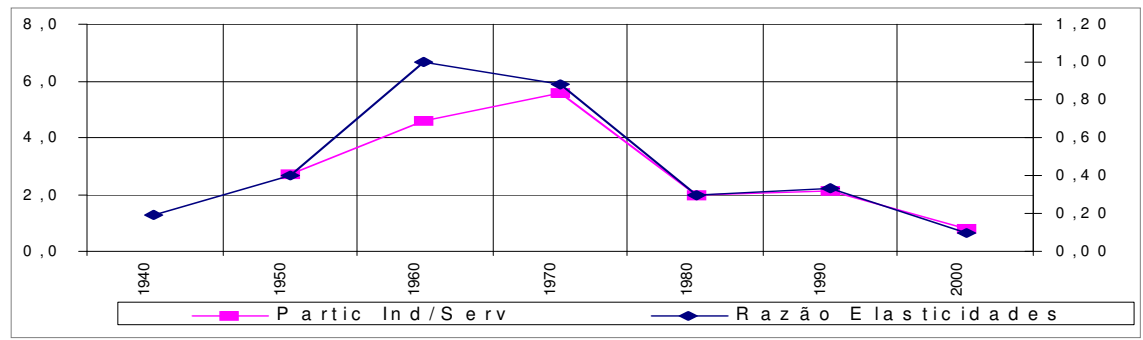

Por outro lado, a elevação da participação dos setores industrial e de serviços, em detrimento da agropecuária, parece estar altamente correlacionada com a razão de elasticidades, que considera tanto a elasticidade-renda das importações como das exportações, como pode ser observado no Gráfico 4.

Para finalizar, utilizamos resultados contidos em trabalho realizado por Bacha e Bonelli (2001), no qual o crescimento da produtividade brasileira é dividido em dois componentes: componente tecnológico puro e componente estrutural. O componente tecnológico refletiria a melhora tecnológica em si, enquanto o componente estrutural espelharia o ganho tecnológico pelo fato de a produção migrar de setores mais intensivos em tecnologia.

Gráfico 5

Produtividade e elasticidade-renda das importações

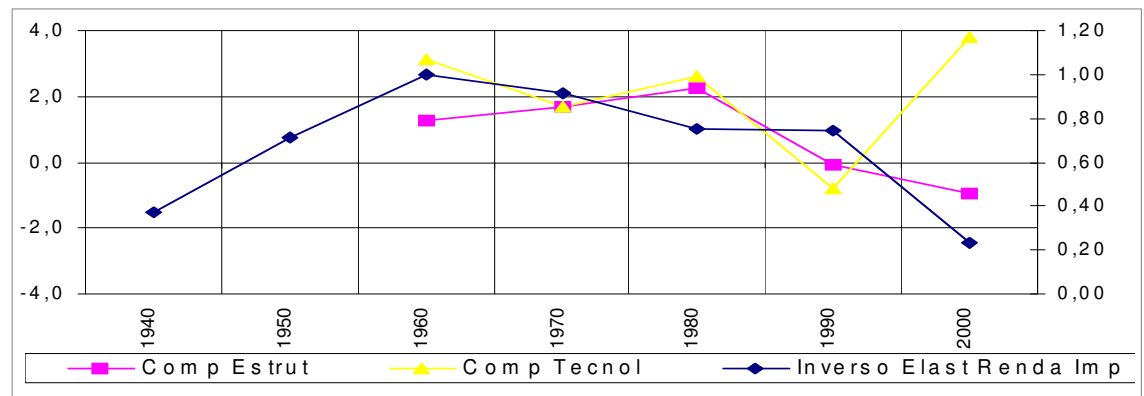


Gráfico 6

Produtividade e razão de elasticidades

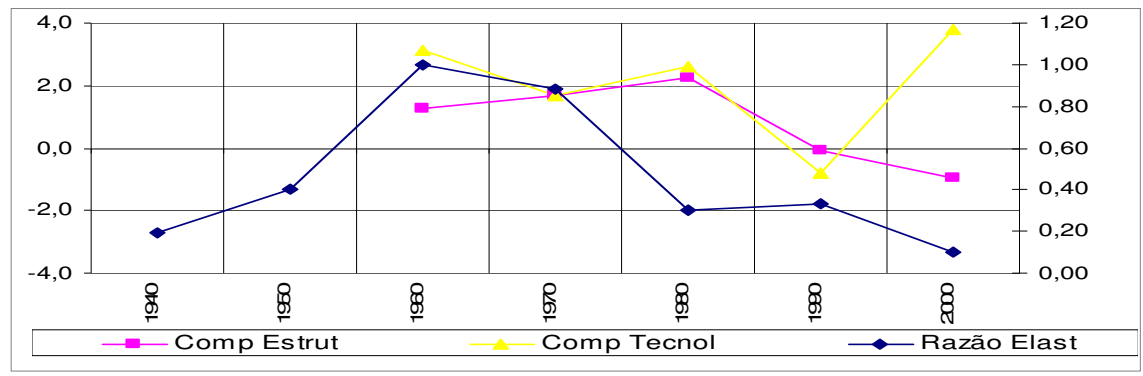

A única relação consistente que se poderia extrair dos Gráficos 5 e 6 é entre componente estrutural da produtividade e elasticidade-renda das importações ou razão de elasticidades. Parece não haver relação do componente tecnológico puro, seja com a elasticidade de importação, seja com a razão das elasticidades.

\section{Considerações finais}

Ao observarmos a história econômica do país entre as décadas de 1930 e 1970, parece evidente que a preocupação em diversificar a estrutura produtiva foi um dos principais objetivos da política econômica. $\mathrm{O}$ expressivo crescimento da renda, nesse período, sugere, então, a conjectura de que a restrição externa (e a estrutura produtiva com a qual ela coevolui) é um fator relevante na experiência brasileira de crescimento econômico.

Os estudos empíricos aqui reportados e comentados, conduzidos com base na abordagem keynesiana de crescimento sob restrição externa, corroboraram a abordagem estruturalista, uma vez que se pode afirmar que entre 1930 e 2004 o crescimento no Brasil foi aquele compatível com o equilíbrio do balanço de pagamentos. Além disso, o lado comercial do equilíbrio externo, ou a razão das elasticidades-renda das importações e exportações, explica a maior parte desse crescimento.

Uma vez validado o poder explicativo dessa abordagem, pode-se utilizá-la para contribuir para a obtenção de uma possível resposta à questão central deste artigo, qual seja: como explicar que uma economia que cresceu à média anual de 6,8\% entre 1932-1980 tenha passado a crescer à média anual de apenas 2,2\% entre 1981-2004?

É possível perceber, já no início da década de 1980, uma abrupta queda na taxa de crescimento. No entanto, segundo os experimentos aqui realizados, não houve, no período, uma quebra estrutural dos parâmetros da Lei de Thirlwall que explicasse esse comportamento. $\mathrm{O}$ equilíbrio mais perverso do balanço de pagamentos nessa década pode ser explicado pela redução no fluxo de capitais, associado a uma valorização da taxa de câmbio real. Ou seja, embora o câmbio real e o fluxo de capitais não tenham se 
mostrado relevantes para o equilíbrio externo no longo prazo, eles podem ser bastante significantes em alguns subperíodos, o que parece ter sido o caso da década de 1980. Assim, pode-se afirmar que a redução no financiamento internacional, juntamente com a valorização do câmbio real entre 1982-1993, fez com que o equilíbrio do balanço de pagamentos ocorresse a uma taxa de crescimento da renda interna mais baixa.

Foi a partir da crise dos anos 1980 e, possivelmente, como conseqüência dela, que o modelo de desenvolvimento de inspiração estruturalista vigente nas décadas anteriores deixou de ser predominante e que o novo modelo econômico emergiu como opção preferencial. Na base teórica inspiradora desse novo modelo, entretanto, não há qualquer consideração da relação entre padrão de especialização da estrutura produtiva e crescimento econômico mediada pela restrição externa. Nesse sentido, os resultados empíricos obtidos neste artigo sugerem precisamente que a não-consideração desse aspecto pode ter gerado um crescimento abaixo do esperado.

Esses resultados empíricos indicam que a partir de 1994 houve uma quebra estrutural nos parâmetros da chamada Lei de Thirlwall, com um crescimento abrupto da elasticidade-renda das importações. Assim sendo, o lado comercial, ou a razão entre a elasticidade-renda das exportações e elasticidade-renda das importações, contribuiu para um crescimento compatível com o equilíbrio externo de 7\% entre 1931-1993 e 1,3\% entre 1994-2004, explicando a enorme perda de dinamismo do crescimento brasileiro.

Detectou-se que a participação das indústrias dinâmicas está significativamente correlacionada com o comportamento da elasticidade-renda das importações. De fato, a reversão nos 1980/1990 do aumento da participação das indústrias dinâmicas que vinha ocorrendo nas décadas anteriores foi acompanhada por um aumento na elasticidade-renda das importações. Por outro lado, a elevação da participação dos setores industrial e de serviços, em detrimento da agropecuária, parece estar altamente correlacionada com a razão de elasticidades. Por fim, utilizando uma decomposição do crescimento da produtividade entre um componente tecnológico puro e um componente estrutural que resulta da migração da produção para setores de maior produtividade, detectou-se que o comportamento da elasticidade-renda das importações e da razão de elasticidades está mais correlacionado com o componente estrutural.

Dado que se pode relacionar essas elasticidades ao padrão de especialização da estrutura produtiva, e que se constatou uma quebra estrutural na elasticidade-renda das importações a partir de 1994, é possível inferir que a estratégia de desenvolvimento do novo modelo econômico, por intermédio das reformas liberalizantes dos anos 1990, reconduziu o país às suas vantagens comparativas estáticas. Conforme o esperado pelos seus idealizadores, isso proporcionou uma elevação expressiva da produtividade. Essa recondução, por 
outro lado, levou a economia brasileira a um padrão de especialização mais perverso do ponto de vista do equilíbrio do setor externo, explicando, assim, a quebra estrutural permanente da taxa de crescimento que dela se seguiu.

Em suma, a contribuição que a abordagem de crescimento sob restrição externa pode oferecer à discussão sobre estratégias de desenvolvimento é que a variável central dessa abordagem, ou seja, a razão das elasticidades-renda, reflete as diferenças entre a natureza e a qualidade dos produtos exportados por diferentes países. Logo, uma discussão qualificada sobre crescimento econômico não pode prescindir nem da análise de eficiência produtiva, como enfatizado pelos adeptos do novo modelo econômico, nem da consideração da adequação do padrão de especialização da estrutura produtiva, como defendido pela teoria estruturalista.

\section{Referências bibliográficas}

AGHION, P.; HOWITT, P. Endogenous growth theory. Cambridge: The MIT Press, 1998.

ARAUJO, R. A.; LIMA, G. T. A structural economic dynamics approach to balanceof-payments-constrained growth. Cambridge Journal of Economics, v. 31, n. 5, p. 755-774, 2007.

AZEVEDO, A. F. Z.; PORTUGAL, M. S. Abertura comercial brasileira e instabilidade da demanda de importações. Nova Economia, v. 8, n. 1, p. 37-63, jul. 1998.

BACHA, E. L.; BONELLI, R. Crescimento e produtividade no Brasil: o que nos diz o registro de Longo Prazo. Texto para Discussão, Maio 2001.

BAER, W. Import substitution and industrialization in Latin America: experiences and interpretations. Latin American Research Review, v. II, n. 1, p. 95-122, 1972.

BAIRAM, E. Levels of economic development and appropriate specification of the Harrod foreing-trade multipler, Journal of Post Keynesian Economics, v. 19, n. 3, p. 337-344, 1997.

BARBOSA-FILHO, N. The balance-of-payments constraint: from balanced trade to sustainable debt. Banca Nazionale del Lavoro Quarterly Review, n. 219, Dec. 2001.

BÉRTOLA, L.; HIGACHI, H.; PORCILE, G. Balance-of-payments-constrained growth in Brazil: a test of Thirlwall's Law, 1890-1973. Journal of Post Keynesian Economics, v. 25, n. 11, 2002.

BIELSCHOWSKY, R. Cinqüenta anos de pensamento da CEPAL: uma resenha. In: (Org.). Cinqüenta anos de pensamento da CEPAL. Editora Record, 2000.

BLECKER, R. Structural roots of U.S. trade problems: income elasticities, secular trends, and hysteresis. Journal of Post Keynesian Economics, v. 14, n. 3, Spring, p. 321-346, 1992.

BRESSER-PEREIRA, L. C.; GALA, P. Por que a poupança externa não promove crescimento. Revista de Economia Política, v. 27, n. 1, p. 3-19, 2007.

; NAKANO, Y. Crescimento econômico com poupança externa? Revista de Economia Política, v. 22, n. 2, p. 3-27, 2003. 
CARVALHO, V. R. A restrição externa e a perda de dinamismo da economia brasileira: investigando as relações entre estrutura produtiva e crescimento econômico. Dissertação (Mestrado)-IPE-FEA-USP, São Paulo, 2006.

CASTRO, A. S.; CAVALCANTI, M. A. F. Estimação de equações de exportação e importação para o Brasil - 1955/95. Pesquisa e Planejamento Econômico, v. 28, n. 1, p. 1-68, 1998.

ELLIOT, D.; RHODD, R. Explaining growth rate differences in highly indebted countries: an extension to Thirlwall and Hussain. Applied Economics, 31, 1999.

FACHADA, M. S. J. F. Um estudo econométrico da balança comercial brasileira: 1975-1988. Dissertação (Mestrado)- PUC, Rio de Janeiro, 1990.

FAGERBERG, J. International competitiveness. The Economic Journal, v. 98, p. $355-374,1988$.

FERREIRA, A. A lei de crescimento de Thirlwall. Dissertação (Mestrado)-Instituto de Economia, Universidade Estadual de Campinas, Unicamp, 2001.

FERREIRA, A. H. B. Testes de estabilidade para a função demanda de importações. Revista Brasileira de Economia, v. 48, n. 3, p. 355-370, 1994.

FRANCO, G. H. B. A inserção externa e o desenvolvimento. Revista de Economia Política, v. 18, n. 3, jul./set. 1998.

HARROD, R. International economics. Cambridge: Cambridge University Press, 1933.

HOLLAND, M.; VIEIRA, F.; CANUTO, O. Economic growth and the balance-ofpayments constraint in Latin America. Investigación Económica, v. LXIII, 247, 2004.

IPEA. A economia brasileira em perspectiva. Rio de Janeiro: Ipea, 1998. v. II.

JAYME JR., F. G. Balance-of-payments-constrained economic growth in Brazil. Revista de Economia Política, v. 23, jan./mar. 2003.

KALDOR, N. The case for regional policies. Scottish Journal of Political Economy, Nov. 1970.

LIMA, G. T.; CARVALHO, V. R. Macrodinâmica do produto e da renda sob restrição externa: a experiência brasileira no período 1930-2004. São Paulo: Departamento de Economia da FEA-USP, 2006. Mimeografado.

LISBOA, M. (Org.). A agenda perdida: diagnósticos e propostas para a retomada do crescimento com maior justiça social. IFB, 2002.

LLERENA, P.; LORENTZ, A. Cumulative causation and evolutionary micro-founded technical change: on the determinants of growth differences. Revue Economique, v. 55 , n. 6 , p. 1191-1214, 2004.

LOPEZ, J.; CRUZ, A. Thirlwall's Law and beyond: the Latin American experience. Journal of Post Keynesian Economics, v. 22, n. 3, Spring, 2000.

McCOMBIE, J. Thirlwall's Law and Balance of Payments constrained growth: a comment on the debate. Applied Economics, 21, 1989.

On the empirics of balance-of-payments-constrained growth. Journal of

Post Keynesian Economics, v. 19, n. 3, 1997. 
McCOMBIE, J.; ROBERTS, M. The role of balance of payments in economic growth. In: SETTERFIELD, Mark (Org.). The economics of demand-led growth: challenging the supply-side vision of the long run. Cheltenham, UK: Edward Elgar, 2002 .

; THIRLWALL, A. Economic growth and the balance of payments constraint. New York: St. Martin's Press, 1994.

Economic growth and balance-of-payments constraint revisited. In: ARESTIS, P.; PALMA, G.; SAWYER, M. (Ed.). Markets, unemployment and economic policy. London: Routledge, 1997. v. 2.

Essays on balance of payments constrained growth - theory and evidence. London: Routledge, 2004.

MORAIS, I. A.; PORTUGAL, M. S. Structural change in the Brazilian demand for imports: a regime switching approach. Latin American Meetings of the Econometric Society, n. 346, 2004.

MOREIRA, M. M. A indústria brasileira nos anos 90 . O que já se pode dizer? In: GIAMBIAGI, F.; MOREIRA, M. M. (Org.). A economia brasileira nos anos 90. Rio de Janeiro: BNDES, 1999.

; CORREIA, P. G. Brazil's trade liberalization and growth: has it failed? INTAL-ITD, 2004. (Occasional Paper, 24).

MORENO-BRID, J. C. On capital flows and the balance-of-payments constrained growth model. Journal of Post Keynesian Economics, v. 21, 1998-1999.

Capital flows, interest payments and the balance-of-payments constrained growth model: a theoretical and an empirical analysis. Metroeconomica, v. 54, n. 2, May 2003.

NAKABASHI, L. Crescimento da economia brasileira e fluxo de capitais a partir da Lei de Thirlwall: 1968-1980 e 1992-2000. In: ENCONTRO NACIONAL DE ECONOMIA POLÍTICA, 11, Vitória, 2006.

O modelo de Thirlwall com variações nas elasticidades. Economia $e$ Sociedade, v. 16, n. 1, p. 93-110, 2007.

NELSON, R.; WINTER, S. An evolutionary theory of economic change. Cambridge, Mass.: Harvard University Press, 1982.

PORTUGAL, M. S. Um modelo de correção de erros para a demanda por importações brasileira. Pesquisa e Planejamento Econômico, v. 22, n. 3, p. 501-540, 1992.

PREBISCH, R. The economic development of Latin America and its principal problems. New York: ECLA, 1950.

RESENDE, M. F. C. Disponibilidade cambial e especificação da função de demanda de importações para o Brasil. Rio de Janeiro: Ipea, 1997. (Texto para Discussão, n. 506).

Crescimento econômico, disponibilidade de divisas e importações no Brasil: um modelo de correção de erros. Pesquisa e Planejamento Econômico, Rio de Janeiro, v. 31, n. 2, p. 289-330, 2001.

; ANDERSON, P. Mudanças estruturais na indústria brasileira de bens de capital. Rio de Janeiro: Ipea, 1999. (Texto para Discussão, n. 420). 
RODRIGUEZ, O. Teoria do subdesenvolvimento da CEPAL. Rio de Janeiro: Forense Universitária, 1981.

SANTOS, A. T. L.; LIMA, G. T.; CARVALHO, V. R. A restrição externa como fator limitante do crescimento econômico brasileiro: um teste empírico. In: ENCONTRO NACIONAL DE ECONOMIA, 23, Natal, dez. 2005. Anais eletrônicos... Disponível em: $<$ www.anpec.org.br>.

SEERS, D. A model of comparative growth rates of the world economy. Economic Journal, Mar. 1962.

SETTERFIELD, M. 'History versus equilibrium' and the theory of economic growth, Cambridge Journal of Economics, v. 21, n. 3, p. 365-378, 1997.

SILVA, A. B. M.; PORTUGAL, M. S.; CECHIN, A. L. Redes neurais artificiais e análise de sensibilidade: uma aplicação à demanda de importações brasileiras, Economia Aplicada, v. 5, n. 4, 2001.

SOLOW, R. A contribution to the theory of economic growth. Quarterly Journal of Economics, 70, 1956.

TAVARES, M. C. Auge e declínio do processo de substituição de importações no Brasil. In: BIELSCHOWSKY, R. (Org.). Cinqüenta anos de pensamento da CEPAL. Editora Record, 2000.

THIRLWALL, A. The balance of payments constraint as an explanation of international growth rates differences. Banca Nazionale del Lavoro Quarterly Review, v. $128,1979$.

Foreign trade elasticities in centre-periphery models of growth and development. Banca Nazionale del Lavoro Quarterly Review, Sept. 1983.

. Reflections on the concept of balance-of-payments-constrained growth. Journal of Post Keynesian Economics, v. 19, n. 3, 1997.

; HUSSAIN, M. The balance of payments constraint, capital flows and growth rates differences between developing countries. Oxford Economic Papers, v. 34, 1982.

VERSPAGEN, B. Evolutionary macroeconomics: a synthesis between neoSchumpeterian and post-Keynesian lines of thought. The Electronic Journal of Evolutionary Modeling and Economic Dynamics, n. 1007. 2002. Disponível em: $<$ www.e-jemed.org/1007]>.

VIEIRA, F. A.; HOLLAND, M. Crescimento econômico secular no Brasil, modelo de Thirlwall e termos de troca. In: ENCONTRO NACIONAL DE ECONOMIA, 23, Natal, dez. 2006. Anais eletrônicos... Disponível em: <www.anpec.org.br>.

WILLIAMSON, J. What Washington mean by policy reform, in Conference Volume of The Progress of Policy Reform in Latin America. Washington, DC: Institute of International Economics, 1990.

ZINI JR., A. A. Funções de exportação e importação para o Brasil. Pesquisa e Planejamento Econômico, v. 18(3), p. 615-662, 1988. 


\section{Anexos}

\section{Anexo 1 - Testes de raiz unitária}

\begin{tabular}{|c|c|c|c|c|c|}
\hline \multicolumn{7}{|c|}{ Testes Dickey-Pantula: duas raízes unitárias } \\
\hline & $\begin{array}{c}\text { Termo } \\
\text { Determinista }\end{array}$ & Defasagem & t-calc. & t-tab. & Conclusão \\
\hline Importação & constante & 0 & -7.37 & -2.90 & Rejeita 2 RUs \\
\hline Renda & nada & 0 & -3.98 & -1.95 & Rejeita 2 RUs \\
\hline Câmbio & nada & 0 & -7.37 & -1.95 & Rejeita 2 RUs \\
\hline
\end{tabular}

\begin{tabular}{|c|c|c|c|c|c|}
\hline \multicolumn{6}{|c|}{ Testes ADF } \\
\hline \multicolumn{6}{|c|}{ Variável: Ln Importações } \\
\hline & & & \multicolumn{3}{|c|}{ Termos Deterministas } \\
\hline & ADF calc. & ADF tab. & t-calc. & t-tab. & Significância \\
\hline \multicolumn{6}{|c|}{ Modelo com Tendência e Constante (9 defasagens) } \\
\hline tendência & -2.87 & -3.48 & 2.63 & 2.79 & não significante \\
\hline constante & & & 2.98 & 3.11 & não significante \\
\hline \multicolumn{6}{|c|}{ Modelo com Constante ( 9 defasagens) } \\
\hline & -1.30 & -2.90 & 1.50 & 2.54 & não significante \\
\hline \multicolumn{6}{|c|}{ Modelo sem Tendência ou Constante ( 9 defasagens) } \\
\hline & 2.077 & -1.95 & & & Aceita Raiz Unitária \\
\hline \multicolumn{6}{|c|}{ Variável: Ln Renda Real } \\
\hline & & & \multicolumn{3}{|c|}{ Termos Deterministas } \\
\hline & ADF calc. & ADF tab. & t-calc. & t-tab. & Significância \\
\hline \multicolumn{6}{|c|}{ Modelo com Tendência e Constante (2 defasagens) } \\
\hline tendência & -0.75 & -3.48 & 1.11 & 3.11 & não significante \\
\hline constante & & & 0.56 & 0 & não significante \\
\hline \multicolumn{6}{|c|}{ Modelo com Constante ( 2 defasagens) } \\
\hline & -1.26 & -2.90 & 1.98 & 0.00 & não significante \\
\hline \multicolumn{6}{|c|}{ Modelo sem Tendência ou Constante (2 defasagens) } \\
\hline & 2.11 & -1.95 & & & Aceita Raiz Unitária \\
\hline \multicolumn{6}{|c|}{ Variável: Ln Câmbio Real } \\
\hline & & & \multicolumn{3}{|c|}{ Termos Deterministas } \\
\hline & ADF calc. & ADF tab. & t-calc. & t-tab. & Significância \\
\hline \multicolumn{6}{|c|}{ Modelo com Tendência e Constante (2 defasagens) } \\
\hline Tendência & -1.47 & -3.48 & -1.21 & 0.00 & não significante \\
\hline constante & & & 1.77 & 3.11 & não significante \\
\hline \multicolumn{6}{|c|}{ Modelo com Constante (2 defasagens) } \\
\hline & -1.37 & -2.90 & 0.71 & 0.00 & não significante \\
\hline \multicolumn{6}{|c|}{ Modelo sem Tendência ou Constante (2 defasagens) } \\
\hline & -1.23 & -1.95 & & & Aceita Raiz Unitária \\
\hline
\end{tabular}

\begin{tabular}{|l|c|c|c|}
\hline \multicolumn{4}{|c|}{ Testes KPSS } \\
\hline \multicolumn{1}{|c|}{ Modelo } & Importações & Câmbio & Renda \\
\hline Tendência & 0.061 & 0.204 & 0.212 \\
\hline Conclusão & $0 \mathrm{RU}$ & $1 \mathrm{RU}$ & $1 \mathrm{RU}$ \\
\hline Constante & 1.090 & 0.211 & 1.160 \\
\hline Conclusão & $1 \mathrm{RU}$ & $0 \mathrm{RU}$ & $1 \mathrm{RU}$ \\
\hline Conclusão Final & 1 RU constante & 1 RU tendência & $1 \mathrm{RU}$ \\
\hline
\end{tabular}

Conclusão: Todos os testes indicam a presença de uma raiz unitária nas três variáveis pesquisadas. 


\section{Anexo 2 - Testes de especificação do VAR}

\begin{tabular}{|c|c|c|}
\hline \multicolumn{3}{|c|}{ Critério de seleção da ordem do VAR } \\
\hline & Valor & Ordem VAR \\
\hline Estatística LR - Significância da maior defasagem & 628.2623 & 1 \\
\hline FPE - Erro final de previsão & $1.67 \mathrm{E}-06$ & 1 \\
\hline \multicolumn{3}{|c|}{ Critérios de informação } \\
\hline AIC (Akaike) & -4.787304 & 1 \\
\hline SC (Schwarz) & -4.395626 & 1 \\
\hline HQ (Hannan-Quinn) & -4.632109 & 1 \\
\hline
\end{tabular}

Assim, todos os critérios indicam que se deve estimar um VAR de ordem 1

\begin{tabular}{|l|c|c|c|c|c|}
\hline \multicolumn{5}{|c|}{ Critério de seleção dos termos deterministas no VAR } \\
\hline \multicolumn{5}{|c|}{ Número de vetores de cointegração } \\
\hline & Modelo 1 & Modelo 2 & Modelo 3 & Modelo 4 & Modelo 5 \\
\hline Estatística Traço & 1 & 1 & 0 & 0 & 0 \\
\hline Estatística Autovalor & 1 & 1 & 0 & 0 & 0 \\
\hline Modelo 1: sem intercepto ou tendência dentro e fora do vetor de cointegração \\
\hline Modelo 2: com intercepto e sem tendência dentro do vetor de cointegração \\
\hline Modelo 3: com intercepto e tendência dentro do vetor de cointegração \\
\hline Modelo 4: com intercepto e tendência dentro e só intercepto fora do vetor de cointegração \\
\hline
\end{tabular}

De acordo com o Princípio de Pantula, deve-se escolher o modelo mais simples que apresente um ou mais vetores de cointegração.

Conclusão: Com base nos critérios acima apontados, foi escolhido um VAR de ordem 1 (VEC de ordem 0) e sem termos deterministas dentro ou fora do vetor de cointegração.

\section{Anexo 3 - Testes cointegração}

\begin{tabular}{|l|c|c|c|c|}
\hline & Estatística traço & $\begin{array}{c}\text { Valor crítico } \\
(5 \%)\end{array}$ & $\begin{array}{c}\text { Estatística } \\
\text { autovalor }\end{array}$ & $\begin{array}{c}\text { Valor crítico } \\
(5 \%)\end{array}$ \\
\hline Nenhum vetor & 85.4 & 24.31 & 79.72 & 17.89 \\
\hline Ao menos 1 vetor & 5.68 & 12.53 & 5.45 & 11.44 \\
\hline $\begin{array}{l}\text { Ao menos 2 } \\
\text { vetores }\end{array}$ & 0.23 & 3.84 & 0.23 & 3.84 \\
\hline
\end{tabular}

Conclusão: Ambas as estatísticas apontam a existência de um vetor de cointegração a $5 \%$ de significância.

\section{Anexo 4 - Teste dos resíduos do VEC}

\begin{tabular}{|l|c|c|c|}
\hline & Jarque-Bera & $\begin{array}{c}\text { Probabilidade } \\
\text { Normalidade }\end{array}$ & Conclusão \\
\hline Importações & 1.84 & $39.9 \%$ & Aceita normalidade \\
\hline Renda & 2.22 & $32.9 \%$ & Aceita normalidade \\
\hline Câmbio & 13.34 & $0.2 \%$ & Rejeita normalidade \\
\hline
\end{tabular}

Conclusão: Os testes dos resíduos apontam para algum problema de normalidade na variável câmbio real. Espera-se que o problema seja solucionado ao considerar uma amostra razoavelmente grande. 


\section{Anexo 5 - Estimação da função importação para o Brasil - Outros estudos}

\begin{tabular}{|l|c|c|l|}
\hline & $\begin{array}{c}\text { Elasticidade- } \\
\text { renda }\end{array}$ & $\begin{array}{c}\text { Elasticidade- } \\
\text { preço }\end{array}$ & \multicolumn{1}{|c|}{ Período } \\
\hline Zini Jr. (1988) & 3.28 & -0.46 & $1970-1986$ \\
\hline Fachada (1990) & 1.19 & -0.38 & $1976 / I I-1988 / I V$ \\
\hline Portugal (1992) & 0.34 & -0.91 & $1976 /$ I-1988/IV \\
\hline Ferreira (1994) & -0.21 & -1.32 & $1981 /$ IV-1989/IV \\
\hline Azevedo et al. (1998) & 2.11 & -5.58 & $1980 / I-1994 / I V$ \\
\hline Castro et al. (1998) & 2.03 & -0.45 & $1956-1995$ \\
\hline Resende (1997) & -0.89 & -0.01 & $1974 /$ II-1988/IV \\
\hline Resende (2001) & 3.31 & -1.39 & $1978 /$ I-1998/IV \\
\hline Silva et al. (2001) & 1.28 & -1.18 & $1994 /$ III-1999/IV \\
\hline Morais e Portugal (2004) & 1.71 & -0.43 & $1947-2002$ \\
\hline Santos; Lima e Carvalho (2006) & 1.77 & não sign & $1947-2004$ \\
\hline
\end{tabular}

Tabela apresentada em Morais e Portugal (2004), com a inclusão das duas últimas linhas.

\section{Anexo 6 - Elasticidades por período}

\begin{tabular}{|l|c|c|c|c|c|}
\hline Período & Ano & Elast M & Elast X & Razão elast & Inverso Elast M \\
\hline $1933-47$ & 1940 & 2.69 & 0.50 & 0.19 & 0.37 \\
\hline $1943-57$ & 1950 & 1.41 & 0.56 & 0.40 & 0.71 \\
\hline $1953-67$ & 1960 & 0.10 & 0.46 & 1.00 & 1.00 \\
\hline $1963-77$ & 1970 & 1.10 & 0.97 & 0.88 & 0.91 \\
\hline $1973-87$ & 1980 & 1.34 & 0.40 & 0.30 & 0.75 \\
\hline $1983-97$ & 1990 & 1.36 & 0.45 & 0.33 & 0.74 \\
\hline $1991-04$ & 2000 & 4.28 & 0.41 & 0.10 & 0.23 \\
\hline
\end{tabular}

